\title{
Comparison of the effect of the aerobic glycolysis inhibitor dichloroacetate and of the Krebs cycle inhibitor LW6 on cellular and humoral alloimmunity
}

\author{
THEODOROS ELEFTHERIADIS ${ }^{1}$, GEORGIOS PISSAS ${ }^{1}$, ATHANASIOS MAVROPOULOS ${ }^{2}$, \\ VASSILIOS LIAKOPOULOS ${ }^{1}$ and IOANNIS STEFANIDIS ${ }^{1}$ \\ Departments of ${ }^{1}$ Nephrology and ${ }^{2}$ Rheumatology and Clinical Immunology, Faculty of Medicine, \\ University of Thessaly, 41110 Larissa, Greece
}

Received August 3, 2017; Accepted September 6, 2017

DOI: $10.3892 /$ br.2017.980

\begin{abstract}
Cell metabolism is altered during T-cell and B-cell activation and differentiation. Clarifying the exact metabolic shifts may lead to the development of new immunosuppressive medications. In this study, the effect of the aerobic glycolysis inhibitor dichloroacetate (DCA) and of the Krebs cycle enzyme malate dehydrogenase 2 (MDH2) inhibitor LW6 on T-cell alloimmune clonal expansion and on alloantibody production, was evaluated. T-cell clonal expansion was assessed in two-way mixed lymphocyte reaction (MLR). Humoral alloimmunity was evaluated by the alloantibody production in one-way MLR. For this purpose, an antibody-mediated complement-dependent cytotoxicity assay was developed in which the supernatants from one-way MLRs were used against resting peripheral blood mononuclear cells (PBMCs) derived from the same individual that contributed the stimulator cells for the respective MLR. DCA had a minimum effect on alloimmune T-cell clonal expansion, whereas it increased humoral immunity significantly. LW6 decreased both alloimmune T-cell proliferation and alloantibody production. The results indicate that MDH2 may be a perfect target for the development of new immunosuppressive medications, especially when inhibition of both cellular and humoral alloimmunity is desirable.
\end{abstract}

\section{Introduction}

Kidney transplantation is the optimal treatment for patients with end-stage kidney disease (1). Although progress in immunosuppressive regimens improved kidney allograft survival mainly by affecting cellular alloimmunity, long-term

Correspondence to: Dr Theodoros Eleftheriadis, Department of Nephrology, Faculty of Medicine, University of Thessaly, Neo Ktirio, Mezourlo Hill, 41110 Larissa, Greece

E-mail: teleftheriadis@yahoo.com

Key words: T-cells, B-cells, alloimmunity, aerobic glycolysis, Krebs cycle, dichloroacetate, LW6, transplantation outcomes remain relatively poor partially due to chronic alloantibody-mediated graft rejection (2). Thus, investigation for new immunosuppressive medications able to suppress both cellular and humoral alloimmunity is of great importance.

Immunometabolism is a field of research with promising pharmacological applications. Concerning adaptive immunity, T-cell activation results in an increase in aerobic glycolysis and glutaminolysis providing the required building blocks for rapid T-cell proliferation and differentiation into effector $\mathrm{T}$ cells (3-5). Although most of the cell energy is acquired by the enhanced aerobic glycolysis, a moderate Krebs cycle and oxidative phosphorylation activity is required for effective T-cell activation, possibly as an extra source of ATP and/or due to the role that mitochondrial ROS play in T-cell activation (6-9). Apart from glucose, upon T-cell activation, glutamine serves as another source of Krebs cycle (10). Glutaminase (GLS) converts glutamine to glutamate. Glutamate is converted to $\alpha$-ketoglutarate, which may enter the Krebs cycle (11). Additionally, in the case of differentiation in regulatory $\mathrm{T}$ cells, fatty acids entering the Krebs cycle is pivotal (3).

B cell metabolism is less well studied (5). There is evidence that upon activation, B cells enhance both aerobic glycolysis and the Krebs cycle in a balanced manner (12-14). Glutamine again serves as a major Krebs cycle source (15). However, differentiated plasma cells are mainly dependent on the Krebs cycle and oxidative phosphorylation for covering the extremely high demands of protein synthesis for ATP. During plasma cell differentiation the transcription factor XBP1 increases mitochondrial mass and function (16). Pyruvate entry into the Krebs cycle is required for the long-term survival of antibody-secreted plasma cells (17). Glutamine again serves as a major source of the Krebs cycle. It is well known that high glutamine concentration is required for antibody production by cultured lymphocytes (18). Analysis of the exometabolome with advanced techniques has shown that massive antibody production is paralleled by glutamine use as a +carbon and energy source (12).

Dichloroacetate (DCA) is an inhibitor of pyruvate dehydrogenase (PDH) kinase (PDK) and by decreasing the phosphorylation of $\mathrm{PDH}$, the pyruvate entry into the Krebs 
cycle is increased instead of its being converted to lactate, thereby decreasing aerobic glycolysis (19). A previous study has shown that in mixed lymphocyte reactions (MLRs), DCA at a concentration of $1 \mathrm{mM}$ decreases aerobic glycolysis assessed by lactate production (20). At this concentration, DCA does not affect significantly cell proliferation but favors CD4+ T-cell apoptosis and differentiation towards a regulatory instead of an effector phenotype (20).

Malate dehydrogenase-2 (MDH2) catalyzes the conversion of malate to oxaloacetate in the Krebs cycle, and the 3-(aryloxyacetylamino)-4-hydroxybenzoic acid derivative LW6 by inhibiting MDH2, thereby suppressing the Krebs cycle (21). A previous study has shown that LW6 at a concentration of $30 \mu \mathrm{M}$ decreases the proliferation of activated T-cells without inducing apoptosis (22). The Krebs cycle is only partially inhibited (22), possibly due to the pyruvatemalate cycle. In this cycle, malate, which is expected to be accumulated in case of MDH2 inhibition, is transferred from the mitochondria to the cytosol where it is converted by the malic enzyme to pyruvate. The formed pyruvate can be converted by PDH to acetyl-CoA and re-enters the Krebs cycle (23). Notably, the malic enzyme is upregulated following T-cell activation (4). Additionally, the pyruvate-malate cycle occurs in activated B cells (15). LW6 increased the expression GLS1 in activated T cells (22), which may also contribute to the only partial inhibition of the Krebs cycle by enhancing the use of glutamine.

Considering the significant role of cell metabolism shifts in the immune response and the possible clinical applications of pharmacological intervention on cell metabolism pathways, in this study, we compared the effect of the aerobic glycolysis inhibitor DCA and Krebs cycle inhibitor LW6 on cellular and humoral alloimmunity. For this purpose, human peripheral blood mononuclear cells (PBMCs) and MLRs were used; and an assay for assessing alloantibody production was developed.

\section{Materials and methods}

Subjects. Blood samples were collected from 4 healthy volunteers (aged 33.5 \pm 6.45 years). All the subjects were male and without a history of blood transfusion in order to exclude any pre-sensitization event. Informed consent was obtained from each individual enrolled in the study. The Ethics Committee of the Faculty of Medicine, University of Thessaly, approved the study protocol.

Cell isolation and culture conditions. PBMCs were isolated from blood with Ficoll-Hypaque density gradient centrifugation using Histopaque-1077 (Sigma-Aldrich; Merck Millipore, Darmstadt, Germany). Isolated PBMCs were counted on a Neubauer chamber (Paul Marienfeld GmbH \& Co. KG, Lauda-Königshofen, Germany) with an optical microscope. Cell viability was assessed using the trypan blue exclusion assay (Sigma-Aldrich; Merck Millipore). Cell cultures were performed in RPMI-1640 medium, supplemented with L-glutamine, $10 \mathrm{mM}$ [4-(2-hydroxyethyl) piperazineethanesulfonic acid] (HEPES) (Sigma-Aldrich; Merck Millipore), $10 \%$ fetal bovine serum (Sigma-Aldrich; Merck Millipore) and antibiotic antimycotic solution (Sigma-Aldrich; Merck
Millipore). Cultures were incubated at $37^{\circ} \mathrm{C}$ in an atmosphere of $95 \%$ relative humidity and $5 \% \mathrm{CO}_{2}$.

Lactate dehydrogenase ( $L D H)$ release cytotoxicity assay. PBMCs $\left(1 \times 10^{5}\right)$ were cultured in 96-well plates for a 7-day period in the presence or not of DCA (Sigma-Aldrich; Merck Millipore) at a concentration of $1 \mathrm{mM}$ or of LW6 (Santa Cruz Biotechnology, Inc., Dallas, TX, USA) at a concentration of $30 \mu \mathrm{M}$. The cytotoxicity of the above compounds was assessed by LDH release assay using the Cytotox Non-Radioactive Cytotoxic Assay kit (Promega Corporation, Madison, WI, USA) according to the manufacturer's protocol. Cytotoxicity was calculated by the equation: Cytotoxicity $(\%)=(\mathrm{LDH}$ in the supernatant $\div$ total LDH) $\times 100$. The experiments were performed in triplicate and the results refer to the mean of the three measurements.

Two-way MLRs and assessment of T-cell proliferation. T-cell proliferation was assessed by assessing cell proliferation in two-way MLRs. Two-way MLRs were performed in 96-well plates in the presence or not of DCA at a concentration of $1 \mathrm{mM}$ or of LW6 at a concentration of $30 \mu \mathrm{M}$ and lasted 7 days. Each member of the couple of individuals contributed to the respective MLR with $5 \times 10^{4}$ PBMCs, bringing the total cell number to $1 \times 10^{5}$ cells/MLR. In parallel, $1 \times 10^{5}$ resting PBMCs from each member were cultured in the same 96-well plate and served as controls.

Cell proliferation was evaluated with Cell Proliferation ELISA (Roche Diagnostics, Indianapolis, IN, USA) using bromodeoxyuridine labeling and immunoenzymatic detection according to the protocol provided by the manufacturer. The proliferation index was calculated using the equation: Proliferation index $(\%)=$ [optical density $(\mathrm{OD})$ derived from each MLR $\div$ mean of the ODs derived from the control resting PBMCs cultures of the two subjects that constituted the specific MLR] x 100. Six such MLRs were performed, each in triplicate and the results refer to the mean of the three measurements.

One-way MLRs and assessment of alloantibody production. One-way MLRs were performed in 24-well plates. Mitomycin C-treated PBMCs $\left(0.5 \times 10^{6}\right.$ cells $)$ were used as stimulator cells. For the mitomycin $\mathrm{C}$ treatment, PBMCs were incubated for $30 \mathrm{~min}$ with $50 \mu \mathrm{g} / \mathrm{ml}$ mitomycin C (SigmaAldrich; Merck Millipore) at $37^{\circ} \mathrm{C}$ and then washed 3 times with complete RPMI-1640. As responder cells, $0.5 \times 10^{6} \mathrm{PBMCs}$ from another individual were used. MLRs lasted for 7 days in the presence or not of $1 \mathrm{mM}$ DCA or $30 \mu \mathrm{M}$ LW6. Then, supernatants from each one-way MLR were harvested to obtain antibodies produced against the stimulator PBMCs, since a 7-day period is enough for the production of IgM and IgG alloantibodies in MLRs (24).

A modification of an antibody-mediated complementdependent cytotoxicity (CDC) assay protocol developed for assessing antigen-specific antibodies in serum was used in order to assess alloantibody production $(25,26)$. In parallel with the above mentioned one-way MLRs, resting untreated PBMCs were cultured in 6-well plates. At the end of the 7-day period of one-way MLRs, resting PBMCs similar to those used as stimulator cells in MLRs, albeit untreated, were counted and seeded in 96 -well plates at a number of $0.5 \times 10^{5}$ and in 
a volume of $50 \mu \mathrm{l}$. To assess antibody-mediated CDC, $50 \mu \mathrm{l}$ of supernatant collected from each respective one-way MLR or 1:2 dilution with complete RPMI-1640 were added into the 96-well plates already seeded with the resting PBMCs serving as target cells. The plates were incubated for $30 \mathrm{~min}$ on ice. Subsequently, $11 \mu \mathrm{l}$ of rabbit complement (Low-Tox ${ }^{\circledR}-\mathrm{H}$ rabbit complement, Cedarlane Corporation, Burlington, Ontario, Canada) were added to each well at a final concentration of $10 \%$. The 96-well plates were incubated for another $2 \mathrm{~h}$ at $37^{\circ} \mathrm{C}$. As a control, $50 \mu 1$ of complete RMPI-1640 were added instead of the one-way MLR supernatant, along with $11 \mu \mathrm{l}$ of rabbit complement.

Since cell-mediated cytotoxicity occurs in the course of an MLR (27), and inevitably LDH is released in the supernatants and the used compounds affect the intensity of the MLRs, we avoided assessing antibody-mediated CDC with $\mathrm{LDH}$ release assay as it would provide us with erroneous data. Instead, we assessed cell survival by measuring the reduction of sodium 2,3-bis(2-methoxy-4-nitro-5-sulfophenyl)-5-[(phenylamino)carbonyl]-2H-tetrazolium (XTT), a yellow tetrazolium salt, to the orange formazan by metabolically viable active target cells. Target cells were incubated with the XTT reagent for $1 \mathrm{~h}$. For this purpose, the TACS XTT assay kit (Trevigen, Gaithersburg, MD, USA) was used according to the manufacturers' protocol provided and cell survival was calculated as cell survival $(\%)=(\mathrm{XTT}$ assay $\mathrm{OD}$ of the control $\div \mathrm{XTT}$ assay OD of the evaluated condition) $\mathrm{x} 100$. Twelve such experiments were performed, each in triplicates and the results refer to the mean of the three measurements.

Statistical analysis. The normality of the evaluated variables was confirmed by the one-sample Kolmogorov-Smirnov test. For comparison of means, paired t-test or one-way repeated measures analysis of variance (ANOVA) followed by Bonferroni's correction test were used. Results were expressed as mean \pm standard deviation $(\mathrm{SD}) . \mathrm{P}<0.05$ was considered statistically significant. The SPSS 13.0 software for Windows (SPSS Inc., Chicago, IL, USA) was used for the statistical analysis.

\section{Results}

At the used concentrations neither DCA nor LW6 was cytotoxic for resting PBMCs. Compared to the untreated PBMCs, in which $\mathrm{LDH}$ release assay detected a cytotoxicity of $11 \pm 0.82 \%$, neither DCA at a concentration of $1 \mathrm{mM}$ nor LW6 at a concentration of $30 \mu \mathrm{M}$ was cytotoxic. Cytotoxicity was $10.75 \pm 0.87 \%$ in case of DCA treatment ( $>>0.05)$ and $11.00 \pm 0.41 \%$ in case of LW6 treatment ( $\mathrm{p}>0.05)$ (Fig. 1).

In two-way MLRs DCA had minor effect on T-cell proliferation, whereas LW6 inhibited T-cell proliferation significantly. In two-way MLRs DCA increased cell proliferation $(\mathrm{p}<0.05)$, but only slightly. The proliferation index was $160.41 \pm 5.66 \%$ in untreated MLRs and $187.99 \pm 13.20 \%$ in DCA-treated MLRs, which corresponds to an alteration rate of $17.5 \%$ (Fig. 2).

LW6 decreased T-cell clonal expansion in two-way MLRs almost to the control values $(\mathrm{p}<0.001)$. In this case, the proliferation index was $116.95 \pm 3.78 \%$ (Fig. 2).

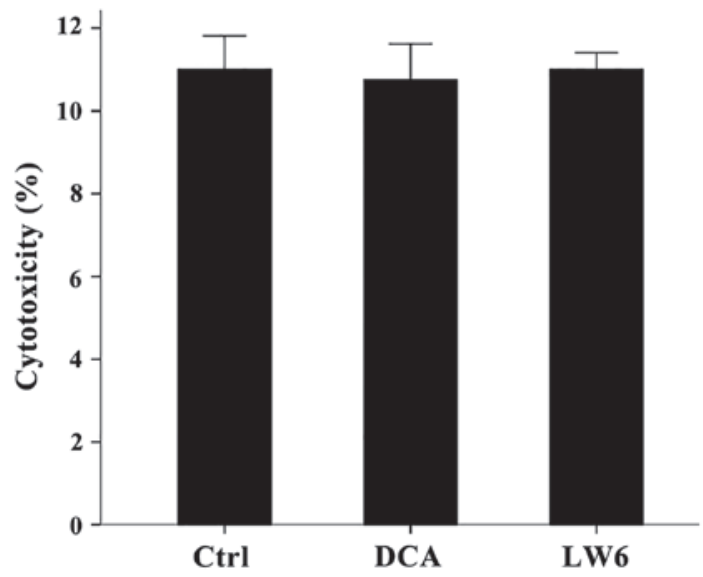

Figure 1. Neither DCA nor LW6 was cytotoxic. Resting PBMCs were cultured for 7 days in the presence or not of $1 \mathrm{mM}$ DCA or $30 \mu \mathrm{M}$ LW6. None of the used compounds were cytotoxic. Error bars correspond to 2 SD. DCA, dichloroacetate; PBMCs, peripheral blood mononuclear cells; SD, standard deviation.

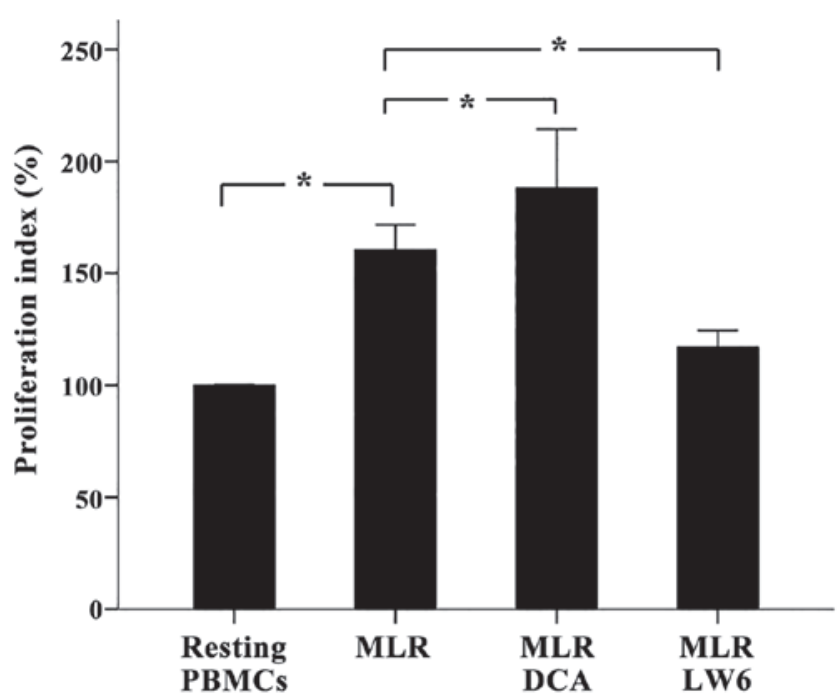

Figure 2. In two-way MLRs, DCA increased T-cell proliferation slightly, whereas LW6 decreased T-cell proliferation. Two-way MLRs lasted 7 days. Compared to untreated MLRs, DCA increased T-cell proliferation but only by a factor of $17.5 \%$, whereas LW6 induced considerable suppression of T-cell proliferation. Six different two-way MLRs were performed. Error bars correspond to $2 \mathrm{SD}$. Statistical significant differences $(\mathrm{p}<0.05)$ of interesting comparisons are denoted with an asterisk. MLRs, mixed lymphocyte reactions; DCA, dichloroacetate; PBMCs, peripheral blood mononuclear cells; $\mathrm{SD}$, standard deviation.

DCA increases alloantibody production in one-way MLRs, whereas LW6 decreases alloantibody production. Antibody-mediated CDC assay revealed that in one-way MLRs alloantibodies were formed. Undiluted or 1:2 diluted supernatants from these MLRs decreased target cell survival significantly to the $64.38 \pm 4.42 \%(\mathrm{p}<0.001)$ and $80.92 \pm 3.63 \%$ $(\mathrm{p}<0.001)$ compared to the control. Notably, compared to undiluted supernatants, 1:2 diluted supernatants decreased cell survival less $(\mathrm{p}<0.001)$ (Fig. 3A and B).

Undiluted supernatants from DCA-treated one way MLRs decreased target cell survival significantly from $64.38 \pm 4.42 \%$ to $43.49 \pm 5.40 \%(\mathrm{p}<0.001)$ and from $80.92 \pm 3.63 \%$ to 

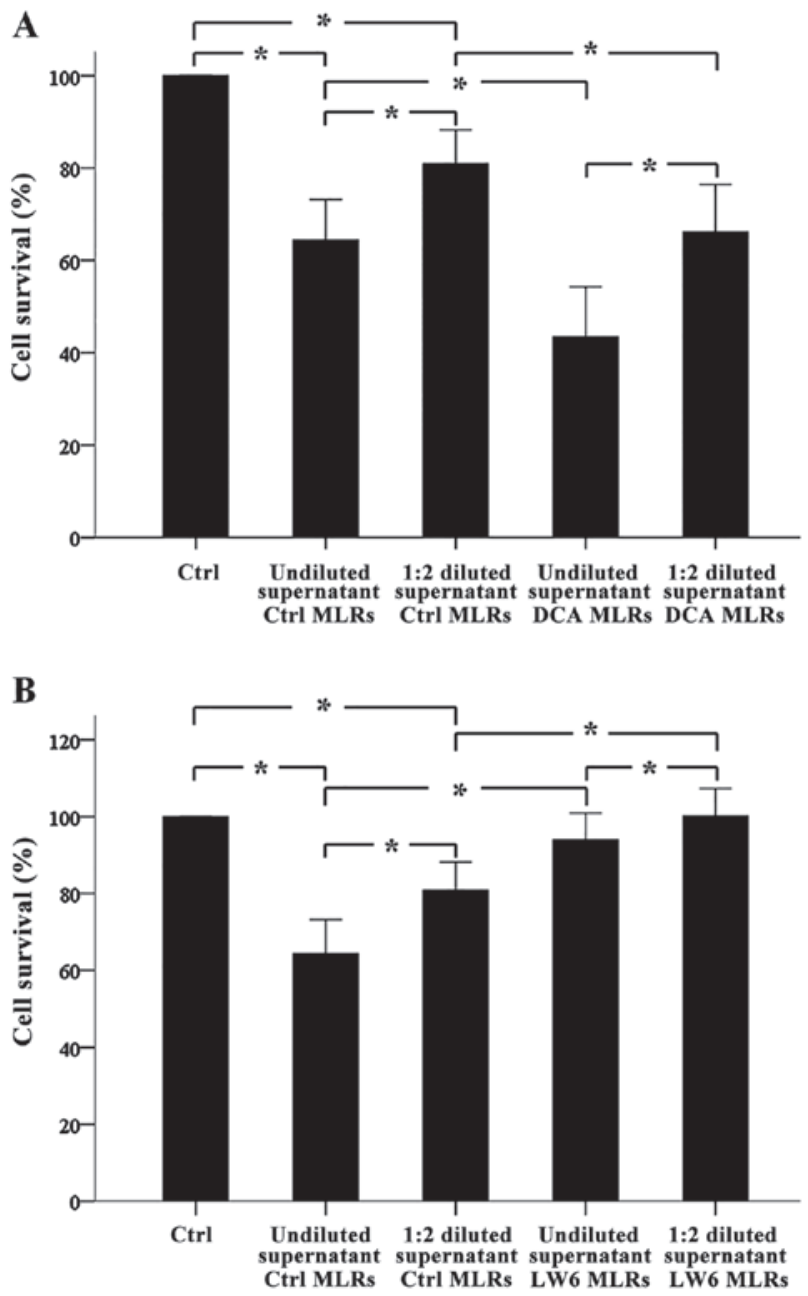

Figure 3. In one-way MLRs, DCA increased alloantibody production, whereas LW6 decreased alloantibody production. One-way MLRs lasted 7 days. Then the supernatants were collected and the production of the antibodies in them was tested with an antibody-mediated CDC assay against PBMCs target cells derived from the subjects who confer the stimulator PMBCs of the respective one-way MLRs. Twelve different one-way MLRs were performed. CDC assay revealed that alloantibodies were present in the supernatants. Of note, when supernatants were used at a 1:2 dilution, less CDC was detected (A and B). CDC assay showed that DCA increased alloantibody production (A), whereas LW6 decreased alloantibody production. Error bars correspond to 2 SD. Statistical significant differences $(\mathrm{p}<0.05)$ of interesting comparisons are denoted with an asterisk. MLRs, mixed lymphocyte reactions; DCA, dichloroacetate; CDC, complementdependent cytotoxicity; PBMCs, peripheral blood mononuclear cells; SD, standard deviation.

$66.22 \pm 5.10 \%(\mathrm{p}<0.001)$, respectively. Diluted supernatants affected cell survival less $(\mathrm{p}<0.001)$. Thus, DCA induced alloantibody production in one-way MLRs (Fig. 3A).

Undiluted or 1:2 diluted supernatants from LW6-treated one way MLRs increased target cell survival significantly from $64.38 \pm 4.42 \%$ to $94.01 \pm 3.47 \%(\mathrm{p}<0.001)$ and from $80.92 \pm 3.63 \%$ to $101.17 \pm 3.57 \%$ ( $\mathrm{p}<0.001$ ), respectively. Diluted supernatants affected cell survival less $(\mathrm{p}<0.001)$. Thus, LW6 inhibited alloantibody production in one-way MLRs (Fig. 3B).

\section{Discussion}

In the present study, the effect of the aerobic glycolysis inhibitor DCA and Krebs cycle enzyme MDH2 inhibitor LW6 on humoral alloimmunity was assessed. For this purpose, non-toxic concentrations of DCA and LW6 were used, which, however, are effective in inhibiting the aerobic glycolysis and Krebs cycle, respectively $(20,22)$. Their effect on T-cell clonal expansion was also assessed.

In consensus with a previous study (20), DCA increased T-cell clonal expansion but only slightly. This is in contrast with another study, which has shown that DCA inhibits T-cell clonal expansion (28). However, in that study T cells were murine, activated with anti-CD3/CD28 antibodies and the supra-pharmacological concentration of $20 \mathrm{mM}$ DCA was used (28). We used MLRs, which is a model of alloimmunity (27), and DCA at a concentration of $1 \mathrm{mM}$, which is close to the blood concentrations of this drug when used for the treatment of hereditary lactic acidosis (19). Nevertheless, besides its minor effect on T-cell proliferation found in this study, DCA may exert an immunosuppressive effect, since it favors CD4+ T-cell differentiation toward a regulatory instead of an effector phenotype (20).

As identified in a previous study, in which isolated $\mathrm{T}$ cells were activated with anti-CD3/CD28 covered beads (22), in this study LW6 also inhibited T-cell clonal expansion in two-way MLRs. However, compared to the role of aerobic glycolysis, the role of Krebs cycle in T-cell activation has not been emphasized as Krebs cycle activity is required for an effective T-cell response (6-10). Thus, regarding the T-cell clonal expansion part of cellular alloimmunity, the inhibitor of aerobic glycolysis DCA had a minor effect, whereas the inhibitor of the Krebs cycle LW6 decreased it significantly.

A number of studies using different murine experimental models have shown varying results regarding the effect of DCA on antibody production. In a previous study it was shown that DCA administration in lupus prone or normal mice enhances serum immunoglobulin levels (29), whereas another study has shown that in lupus prone mice DCA had no effect on the levels of anti-dsDNA IgG (9). On the other hand, in a murine model of collagen type II-induced arthritis, DCA alleviated arthritis only in female mice, in which it decreased anti-collagen type II antibodies without affecting the $\mathrm{T}$ cell response (30). In addition, although upon activation murine B-cells exhibit a balanced increase in lactate production and oxygen consumption, the induction of glycolysis is critical for B-cell proliferation and antibody production since DCA abrogated both of these processes (14). However, in that study, the human B cells, when used, were isolated and stimulated with a TLR9 activator (14).

In our model of alloimmunity, DCA increased alloantibody production in one-way MLRs. This may be attributed to the direct effect of DCA on B cells. Since plasma cells are mainly dependent on the Krebs cycle for covering their high energy requirements $(12,16-18)$, DCA-induced increased pyruvate entry into the mitochondria may enhance their ability to produce antibodies. However, an indirect effect cannot be excluded. During T-cell proliferation, enhanced aerobic glycolysis produced large amounts of lactate. Lactate enhances arginase-1 expression on myeloid-derived suppressor cells (31), which then can suppress antibody production $(32,33)$. By decreasing lactate production, DCA may decrease arginase-1 expression and consequently enhance antibody production. Regardless of the exact molecular mechanism, our results 
indicate that although DCA has been already used for the treatment of hereditary lactic acidosis and is well-tolerated (19), it is not a good candidate as an immunosuppressant in the field of transplantation, where chronic antibody-mediated rejection plays a significant role in late graft loss.

The inhibitor of the Krebs cycle LW6 inhibited alloantibody production significantly. This may be the indirect result of the inhibition of T-cell clonal expansion by LW6, but it may also be the direct effect of the Krebs cycle inhibition on plasma cells. As already noted, plasma cells are dependent on the Krebs cycle for covering the high energy demands for the high protein synthesis $(12,16-18)$. The Krebs cycle and the consequent oxidative phosphorylation are more effective than aerobic glycolysis in ATP production. Every $12 \mathrm{~h}$, a blood-derived plasma cell can produce up to $1.7 \mathrm{ng}$ of antibodies (34), whereas it has been calculated that for each peptide bond formation 7.52 molecules of ATP are required (35). It is of note that at least in T cells, the Krebs cycle is not totally inhibited by LW6 (22), possibly due to the pyruvate-malate cycle and increased GLS1 expression $(11,23)$. This prevents energy collapse of the T cells and may explain the lack of apoptosis when they are treated with LW6 (22). It remains to be elucidated if the same occurs in B cells and plasma cells. Reducing T-cell proliferation and antibody production without affecting cell survival is a feature that may mean rapid reversibility of the LW6 immunosuppressive effect when needed, for instance in the case of a life-threatening infection. Regardless of the exact molecular mechanism, the ability of LW6 to inhibit both cellular and humoral alloimmunity renders $\mathrm{MDH} 2$ a possible target for the development of new immunosuppressive medications.

In conclusion, the inhibitor of aerobic glycolysis DCA exerts a minor effect on alloimmune T-cell clonal expansion, while it enhances alloantibody production. The inhibitor of the Krebs cycle LW6 suppresses both alloimmune T-cell clonal expansion and alloantibody production. These results indicate that MDH2 may be an optimal target for the development of new immunosuppressive medications, especially when inhibition of both cellular and humoral alloimmunity is required.

\section{References}

1. Wolfe RA, Ashby VB, Milford EL, Ojo AO, Ettenger RE, Agodoa LY, Held PJ and Port FK: Comparison of mortality in all patients on dialysis, patients on dialysis awaiting transplantation, and recipients of a first cadaveric transplant. N Engl J Med 341: 1725-1730, 1999.

2. Hricik DE: Transplant immunology and immunosuppression: Core curriculum 2015. Am J Kidney Dis 65: 956-966, 2015.

3. Michalek RD, Gerriets VA, Jacobs SR, Macintyre AN, MacIver NJ, Mason EF, Sullivan SA, Nichols AG and Rathmell JC: Cutting edge: Distinct glycolytic and lipid oxidative metabolic programs are essential for effector and regulatory $\mathrm{CD}^{+}{ }^{+} \mathrm{T}$ cell subsets. J Immunol 186: 3299-3303, 2011.

4. Wang R, Dillon CP, Shi LZ, Milasta S, Carter R, Finkelstein D, McCormick LL, Fitzgerald P, Chi H, Munger J, et al: The transcription factor Myc controls metabolic reprogramming upon T lymphocyte activation. Immunity 35: 871-882, 2011.

5. Caro-Maldonado A, Gerriets VA and Rathmell JC: Matched and mismatched metabolic fuels in lymphocyte function. Semin Immunol 24: 405-413, 2012.

6. Roos D and Loos JA: Changes in the carbohydrate metabolism of mitogenically stimulated human peripheral lymphocytes. II. Relative importance of glycolysis and oxidative phosphorylation on phytohaemagglutinin stimulation. Exp Cell Res 77: 127-135, 1973.
7. Chang $\mathrm{CH}$, Curtis JD, Maggi LB Jr, Faubert B, Villarino AV, O'Sullivan D, Huang SC, van der Windt GJ, Blagih J, Qiu J, et al: Posttranscriptional control of $\mathrm{T}$ cell effector function by aerobic glycolysis. Cell 153: 1239-1251, 2013.

8. Sena LA,Li S, Jairaman A, Prakriya M,Ezponda T, Hildeman DA Wang CR, Schumacker PT, Licht JD, Perlman H, et al: Mitochondria are required for antigen-specific $\mathrm{T}$ cell activation through reactive oxygen species signaling. Immunity 38: 225-236, 2013

9. Yin Y, Choi SC, Xu Z, Zeumer L, Kanda N, Croker BP and Morel L: Glucose oxidation is critical for $\mathrm{CD}^{+} \mathrm{T}$ cell activation in a mouse model of systemic lupus erythematosus. J Immunol 196: 80-90, 2016.

10. Bental M and Deutsch C: Metabolic changes in activated T cells: An NMR study of human peripheral blood lymphocytes. Magn Reson Med 29: 317-326, 1993.

11. Matés JM, Segura JA, Martín-Rufián M, Campos-Sandoval JA, Alonso FJ and Márquez J: Glutaminase isoenzymes as key regulators in metabolic and oxidative stress against cancer. Curr Mol Med 13: 514-534, 2013.

12. Garcia-Manteiga JM, Mari S, Godejohann M, Spraul M, Napoli C, Cenci S, Musco G and Sitia R: Metabolomics of B to plasma cell differentiation. J Proteome Res 10: 4165-4176, 2011.

13. Dufort FJ, Gumina MR, Ta NL, Tao Y, Heyse SA, Scott DA, Richardson AD, Seyfried TN and Chiles TC: Glucose-dependent de novo lipogenesis in B lymphocytes: A requirement for atp-citrate lyase in lipopolysaccharide-induced differentiation. J Biol Chem 289: 7011-7024, 2014.

14. Caro-Maldonado A, Wang R, Nichols AG, Kuraoka M, Milasta S, Sun LD, Gavin AL, Abel ED, Kelsoe G, Green DR, et al: Metabolic reprogramming is required for antibody production that is suppressed in anergic but exaggerated in chronically BAFF-exposed B cells. J Immunol 192: 3626-3636, 2014.

15. Le A, Lane AN, Hamaker M, Bose S, Gouw A, Barbi J, Tsukamoto T, Rojas CJ, Slusher BS, Zhang H, et al: Glucoseindependent glutamine metabolism via TCA cycling for proliferation and survival in B cells. Cell Metab 15: 110-121, 2012.

16. Shaffer AL, Shapiro-Shelef M, Iwakoshi NN, Lee AH, Qian SB, Zhao H, Yu X, Yang L, Tan BK, Rosenwald A, et al: XBP1, downstream of Blimp-1, expands the secretory apparatus and other organelles, and increases protein synthesis in plasma cell differentiation. Immunity 21: 81-93, 2004.

17. Lam WY, Becker AM, Kennerly KM, Wong R, Curtis JD, Llufrio EM, McCommis KS, Fahrmann J, Pizzato HA, Nunley RM, et al: Mitochondrial pyruvate import promotes long-term survival of antibody-secreting plasma cells. Immunity 45: 60-73, 2016.

18. Crawford $\mathbf{J}$ and Cohen $\mathrm{HJ}$ : The essential role of L-glutamine in lymphocyte differentiation in vitro. J Cell Physiol 124: 275-282, 1985.

19. Stacpoole PW: The pharmacology of dichloroacetate. Metabolism 38: 1124-1144, 1989

20. Eleftheriadis T, Sounidaki M, Pissas G, Antoniadi G, Liakopoulos V and Stefanidis I: In human alloreactive CD4+ T-cells, dichloroacetate inhibits aerobic glycolysis, induces apoptosis and favors differentiation towards the regulatory T-cell subset instead of effector T-cell subsets. Mol Med Rep 13: 3370-3376, 2016.

21. Lee K, Ban HS, Naik R, Hong YS, Son S, Kim BK, Xia Y, Song KB, Lee HS and Won M: Identification of malate dehydrogenase 2 as a target protein of the HIF-1 inhibitor LW6 using chemical probes. Angew Chem Int Ed Engl 52: 10286-10289, 2013.

22. Eleftheriadis T, Pissas G, Antoniadi G, Liakopoulos V and Stefanidis I: Malate dehydrogenase-2 inhibitor LW6 promotes metabolic adaptations and reduces proliferation and apoptosis in activated human T-cells. Exp Ther Med 10: 1959-1966, 2015.

23. Friedman B, Goodman EH Jr, Saunders HL, Kostos V and Weinhouse S: Estimation of pyruvate recycling during gluconeogenesis in perfused rat liver. Metabolism 20: 2-12, 1971.

24. Rümke HC, Terpstra FG, Huis B, Out TA and Zeijlemaker WP: Immunoglobulin production in human mixed lymphocyte cultures: Implications for co-cultures of cells from patients and healthy donors. J Immunol 128: 696-701, 1982.

25. Konishi E, Kitai Y and Kondo T: Utilization of complementdependent cytotoxicity to measure low levels of antibodies: Application to nonstructural protein 1 in a model of Japanese encephalitis virus. Clin Vaccine Immunol 15: 88-94, 2008. 
26. Eleftheriadis T, Pissas G, Sounidaki M, Antoniadi G, Antoniadis N, Liakopoulos V and Stefanidis I: In human cell cultures, everolimus is inferior to tacrolimus in inhibiting cellular alloimmunity, but equally effective as regards humoral alloimmunity. Int Urol Nephrol: May 15, 2017 (Epub ahead of print).

27. Sato T, Deiwick A, Raddatz G, Koyama K and Schlitt HJ: Interactions of allogeneic human mononuclear cells in the two-way mixed leucocyte culture (MLC): Influence of cell numbers, subpopulations and cyclosporin. Clin Exp Immunol 115 301-308, 1999.

28. Ostroukhova M, Goplen N, Karim MZ, Michalec L, Guo L, Liang Q and Alam R: The role of low-level lactate production in airway inflammation in asthma. Am J Physiol Lung Cell Mol Physiol 302: L300-L307, 2012.

29. Cai P, Boor PJ, Khan MF, Kaphalia BS, Ansari GA and Konig R Immuno- and hepato-toxicity of dichloroacetic acid in $\mathrm{MRL}^{+/+}$ and $\mathrm{B}_{6} \mathrm{C}_{3} \mathrm{~F}_{1}$ mice. J Immunotoxicol 4: 107-115, 2007.

30. Bian L, Josefsson E, Jonsson IM, Verdrengh M, Ohlsson C, Bokarewa M, Tarkowski A and Magnusson M: Dichloroacetate alleviates development of collagen II-induced arthritis in female DBA/1 mice. Arthritis Res Ther 11: R132, 2009.
31. Ohashi T, Akazawa T, Aoki M, Kuze B, Mizuta K, Ito Y and Inoue N: Dichloroacetate improves immune dysfunction caused by tumor-secreted lactic acid and increases antitumor immunoreactivity. Int J Cancer 133: 1107-1118, 2013.

32. Lelis FJN, Jaufmann J, Singh A, Fromm K, Teschner AC, Pöschel S, Schäfer I, Beer-Hammer S, Rieber N and Hartl D: Myeloid-derived suppressor cells modulate B-cell responses. Immunol Lett 188: 108-115, 2017.

33. Simioni PU, Fernandes LG and Tamashiro WM: Downregulation of L-arginine metabolism in dendritic cells induces tolerance to exogenous antigen. Int J Immunopathol Pharmacol 30: 44-57, 2017.

34. Bromage E, Stephens R and Hassoun L: The third dimension of ELISPOTs: Quantifying antibody secretion from individual plasma cells. J Immunol Methods 346: 75-79, 2009.

35. Aoyagi Y, Tasaki I, Okumura J and Muramatsu T: Energy cost of whole-body protein synthesis measured in vivo in chicks. Comp Biochem Physiol A Comp Physiol 91: 765-768, 1988. 